\title{
O apoio matricial em saúde realizado por terapeutas ocupacionais no Sistema Único de Saúde
}

\author{
Bruna de Oliveira Jacinto, Camila de Souza Rodrigues, Bruno Souza Bechara Maxta, \\ Alessandro Rodrigo Pedroso Tomasi
}

Universidade Federal de Minas Gerais - UFMG, Belo Horizonte, MG, Brasil.

\begin{abstract}
Resumo: Introdução: O terapeuta ocupacional é um dos profissionais que pode compor a equipe multiprofissional que desenvolve o trabalho de apoio matricial no Sistema Único de Saúde (SUS). Objetivo: Este estudo teve como objetivo caracterizar a prática de apoio matricial em saúde realizado pelo terapeuta ocupacional no SUS a partir de uma pesquisa bibliográfica realizada em periódicos brasileiros de terapia ocupacional. Método: Foram selecionados cinco artigos que compuseram o estudo. Para análise dos materiais, foram estabelecidas a priori as seguintes categorias: os tipos de serviço de saúde onde é realizado o apoio matricial pelo profissional; os profissionais envolvidos com o apoio matricial; a população e as situações de saúde ou condições sociais trabalhadas; os objetivos do apoio matricial; as características das intervenções e os desafios enfrentados pelo terapeuta ocupacional. A análise dos dados foi realizada a partir da descrição dos dados. Resultados: $\mathrm{O}$ apoio matricial foi apresentado como atribuição multiprofissional na atenção primária à saúde (APS). O público-alvo foram crianças, adultos, idosos, familiares, cuidadores e profissionais. As demandas para o apoio matricial foram assistenciais, sociais e em educação permanente em saúde. As ações tiveram como objetivos instrumentalizar os profissionais com ferramentas para o cuidado integral na APS e implementar ações, em projetos terapêuticos e institucionais compartilhados, voltadas ao desempenho ocupacional, ao pertencimento e à participação da pessoa em sua comunidade, bem como ao controle social no SUS. Conclusão: Apresentou-se como desafio a fundamentação para a prática do terapeuta ocupacional no apoio matricial em saúde.
\end{abstract}

Palavras-chave: Terapia Ocupacional, Apoio Matricial, Sistema Único de Saúde.

\section{The matrix support health by occupational therapists in Brazilian Unified Health System}

\begin{abstract}
Introduction: The occupational therapist is one of the professionals that composes multidisciplinary team that develops the matrix support in the Unified Health System (UHS). Objective: This study aimed to describe the matrix support practice undertaken by occupational therapists in UHS based on a bibliographical research performed in Brazilian occupational therapy journals. Method: Five articles composed this study. The analysis was previously established with the following categories: types of health service where the matrix support is performed; professional involved with the matrix support; population and health or social conditions; matrix support objectives; intervention features and occupational therapists' challenges. Data analysis was performed from the description of the data. Results: Matrix support was presented as a multiprofessional assignment in Primary Health Care (PHC). The target audience were children, adults, the elderly, familily members, caregivers and health professionals. Health assistance, social assistance and continuous health education were the matrix support demands. The objectives were to equip the professionals with health technologies for integral care in PHC and to implement actions, in shared therapeutic and institutional projects focused on occupational performance, belonging and social participation on their community, just as social control in UHS. Conclusion: The practice validity was presented as the mainly challenge for the matrix support.
\end{abstract}

Keywords: Occupational Therapy, Matrix Support, Unified Health System.

Autor para correspondência: Bruno Souza Bechara Maxta, Escola de Educação Física, Fisioterapia e Terapia Ocupacional, Universidade Federal de Minas Gerais, Av. Presidente Antônio Carlos, 6627, Campus Pampulha, CEP 31270-901, Belo Horizonte, MG, Brasil, e-mail: brunobechara@ufmg.br Recebido em Dez. 7, 2015; $1^{\text {a }}$ Revisão em Mar. 15, 2016; 2ª Revisão em Maio 9, 2016; Aceito em Jul. 7, 2016. 


\section{Introdução}

O Sistema Único de Saúde (SUS) representa um conjunto de ações e de serviços em saúde de caráter público com a finalidade de promover a saúde como um direito social garantido pelo Estado. O SUS possui como princípios doutrinários a universalidade, representada pela garantia do acesso aos serviços de saúde para todos, a integralidade, como o conjunto de açôes que visa organizar as ofertas às necessidades de saúde das pessoas, e a equidade, de forma a diminuir as desigualdades assistenciais desse sistema (BRASIL, 1990). As ações e os serviços do SUS estáo organizados em torno das diretrizes de regionalização, hierarquização, descentralização e participação da comunidade, e integrados pelos níveis de atenção primária à saúde (APS), atenção ambulatorial especializada e hospitalar em regióes de saúde (BRASIL, 2011a).

As redes de atenção à saúde (RAS) são apresentadas como um desenho organizacional para o planejamento interfederativo da saúde, de forma a atender a diversidade das demandas. Mendes (2010) colabora para o entendimento das RAS ao defini-las como organizaçóes complexas com diferentes serviços de saúde presentes, com objetivos comuns, e que ofertam uma atenção à saúde continuada e resolutiva à população adscrita, respeitando as diretrizes organizativas do sistema de saúde. Ainda, prevê que novas práticas e experiências, no processo de construção da saúde, sejam implementadas.

A APS é a porta de entrada preferencial para a assistência à saúde nas RAS. A Estratégia Saúde da Família (ESF) é um dos modelos de saúde que visam reorganizar a APS por meio da expansão dos serviços e qualificação assistencial pela adscrição familiar e comunitária. Os seus objetivos buscam promover assistência integral por meio de intervençóes de promoção de saúde, prevenção de doenças e agravos, e de práticas curativas e reabilitadoras. As equipes de referência dos serviços da APS coordenam a atenção à saúde de um determinado território, trabalhando de forma integral, longitudinal, cooperativa, regionalizada e interdependente com os demais serviços existentes nas RAS (BRASIL, 2011b).

Os Núcleos de Apoio à Saúde da Família (NASF) são arranjos organizacionais multiprofissionais que ampliam o leque assistencial das equipes de referência na APS. Auxiliam, portanto, na compreensão e na intervençấo sobre os problemas e as necessidades de saúde identificadas nos territórios. Os NASF não se caracterizam como porta de entrada assistencial, mas como oferta assistencial amparada pelo conceito de apoio matricial em saúde (BRASIL, 2009).
A concepção teórica e metodológica Paideia oferece suporte ao desenvolvimento do apoio matricial, independente do nível de atenção à saúde envolvido com os profissionais. As dimensões do conhecimento, dos afetos e do poder nos processos de trabalho em saúde fundamentam o método para a construção de relaçôes comunicativas entre os profissionais, para a ampliação da sua capacidade e para a identificaçấo de informaçôes, análises e estabelecimentos de açôes conjuntas e ampliadas em saúde. A cogestão das relaçôes interprofissionais, expressa pelo diálogo e pelo compartilhamento de conhecimentos e de poder, é apresentada, portanto, como um dos fundamentos para o apoio matricial em saúde no SUS (CAMPOS et al., 2014).

O apoio matricial em saúde pode ser apresentado como prática de retaguarda assistencial e suporte técnico pedagógico às equipes de saúde. Essa abordagem realiza-se no cotidiano das práticas profissionais e objetiva operacionalizar ideias e açóes em saúde por meio do acompanhamento e formaçáo de coletivos organizados e corresponsáveis no trabalho interdisciplinar e compartilhado com os usuários. $\mathrm{O}$ apoio matricial promove espaços de comunicação e/ou de assistência conjunta em que fluxos na rede de atenção à saúde e saberes conceituais e técnicos são compartilhados entre os profissionais e os usuários da saúde (OLIVEIRA; CAMPOS, 2015; CAMPOS; DOMITTI, 2007).

Uma prática de apoio matricial pode estabelecer-se em um espaço coletivo protegido de encontros periódicos entre os profissionais, com diferentes experiências e formações técnicas, para reflexão, planejamento e intervenção sobre as suas práticas. A estratégia de discussão de casos reais, ou de temas de interesse e relevantes ao contexto institucional, ou da clínica, é utilizada como condução do apoio. As análises dos casos, ou dos temas, sugerem que os profissionais encaminhem tarefas - busca de informaçôes e realização de intervençóes - estruturadas em planos de intervenção que, periodicamente, são reavaliados em consideração à nova conjuntura dos casos, ou dos temas, com possibilidades de redirecionamento deles. A comunicaçáo e o diálogo sobre a prática possibilita ao apoiador matricial analisar as informaçôes institucionais, as intençôes dos profissionais e o envolvimento com os usuários, de forma a envolver-se e estimular novas açóes em saúde no cotidiano do trabalho em saúde (FIGUEIREDO; CAMPOS, 2014).

A prática do apoiador matricial pressupóe: assumir não somente o papel de apoiador, mas de agente de processos de mudança; articular os objetivos institucionais aos saberes e interesses dos 
trabalhadores e usuários; incluir-se nos espaços de comunicação, de deliberação e assistência; permitir-se pensar e fazer sobre os desejos de quem participa do apoio matricial; trabalhar as demandas pela inclusão de ofertas e estímulos a novas práticas coletivas; estimular a produção de novos conhecimentos, de novas relaçôes de afeto e de poder; diversificar os lugares e os espaços da prática do apoio matricial (CAMPOS et al., 2014).

O apoio matricial, na legislação da saúde brasileira, é apontado apenas no âmbito da APS por meio dos NASF (BRASIL, 2011b), embora essa prática seja possível em quaisquer dos níveis de atenção do SUS, como propóe Campos (1998). O terapeuta ocupacional é apresentado como um dos profissionais que podem compor essa e outras equipes de apoio multidisciplinar em serviços de saúde, em serviços ambulatoriais e hospitalares (BEIRÃO; ALVES, 2010). Como apoiador matricial na APS, esse profissional promove açóes na esfera individual, coletiva e comunitária, no âmbito da prevenção de doenças e agravos, reabilitação e da promoção da saúde, considerando o desempenho ocupacional das pessoas em seu cotidiano de cuidado e processos de participação social (JARDIM; AFONSO; PIRES, 2008).

Entende-se que o apoio matricial em saúde pode viabilizar o trabalho do terapeuta ocupacional no apoio técnico e pedagógico aos profissionais diante das questóes ocupacionais que envolvem os cuidados em saúde nos diferentes níveis assistenciais. Por considerar a necessidade de reconhecimento e da importância dessa prática pelo terapeuta ocupacional, este artigo tem como objetivo caracterizar o apoio matricial realizado pelo terapeuta ocupacional no SUS.

\section{Método}

Tratou-se de um estudo descritivo, realizado por meio de pesquisa bibliográfica, conforme proposto por Gil (2002). Para esse autor, a pesquisa bibliográfica é um tipo de estudo estruturado, realizado a partir de fontes secundárias, com objetivo de organizar as informaçôes disponíveis sobre determinado tema em publicações periódicas e/ou livros indexados.

Esse tipo de modalidade de pesquisa é aplicado em estudos de revisão de literatura por meio das etapas: escolha do tema; levantamento bibliográfico preliminar; formulação do problema; elaboração do plano provisório de estudo do assunto; busca das fontes bibliográficas; leitura do material; fichamento das informaçôes identificadas; organização lógica do assunto e redação final do texto (GIL, 2002).
O processo de elaboraçáo do estudo se iniciou com a definição do tema - Terapia Ocupacional e Apoio Matricial em Saúde - e da pergunta de pesquisa - "Como os terapeutas ocupacionais realizam o apoio matricial em saúde?”.

Para responder à pergunta, foram selecionados os periódicos Cadernos de Terapia Ocupacional da Universidade Federal de São Carlos (UFSCar) e Revista de Terapia Ocupacional da Universidade de Sáo Paulo (USP). Justifica-se a escolha por serem os periódicos que tratam sobre a temática da Terapia Ocupacional de maior circulação entre a comunidade profissional e que servem como referência e estímulo para a divulgação e desenvolvimento da prática profissional.

Foi estruturado um plano de estudo com as seguintes categorias: tipo de serviço de saúde onde é realizado o apoio matricial pelo terapeuta ocupacional; os profissionais que realizam o apoio matricial com o terapeuta ocupacional; a populaçáo atendida pelo apoio matricial; as situações de saúde ou condições sociais trabalhadas; os objetivos do apoio matricial pelo terapeuta ocupacional; as características dessas intervençóes; os desafios enfrentados pelo terapeuta ocupacional no desenvolvimento dessa abordagem de trabalho.

A expressão "apoio matricial" foi utilizada como palavra-chave para a busca de materiais condizentes ao tema de pesquisa nos portais dos periódicos Cadernos de Terapia Ocupacional da UFSCar e Revista de Terapia Ocupacional da USP, realizada no mês de outubro de 2014 .

Foram utilizados como critérios de inclusão artigos que caracterizaram práticas de apoio matricial por terapeutas ocupacionais nos seus serviços de atuação entre os anos 2010 e 2014. Foram excluídos da busca os artigos que náo responderam aos critérios de inclusão, bem como os de revisão bibliográfica.

A análise dos dados pautou-se pela leitura dos materiais e pela descrição e comparaçáo das informaçóes a partir do plano de estudos proposto. Foram confeccionadas fichas não padronizadas de registro de informaçóes a fim de organizar e classificar os dados. Quadros demonstrativos de informaçóes foram utilizados para a apresentação dos resultados e direcionamento das discussões.

\section{Resultados e Discussão}

Como resultados da busca bibliográfica, foram encontrados 13 materiais. Destes, cinco foram selecionados pelos critérios de inclusão estabelecidos e identificados como artigos de pesquisa (A1 e A4), 
relatos de experiência (A2 e A3) e comunicação livre (A5) (Tabelas 1 e 2).

Os artigos originais resultantes de pesquisa buscaram valorizar a prática dos profissionais inseridos no NASF, suas atribuiçóes, realizaçóes e desafios para a formação profissional (A1), bem como examinou a percepção de residentes terapeutas ocupacionais nos serviços de saúde sobre a prática do apoio matricial considerado a partir de experiências assistenciais (A4). Os relatos de experiência buscaram a compreensão e a análise das açôes do terapeuta ocupacional em um programa de residência multiprofissional em saúde da família e a sua transformação por meio das experiências realizadas (A2), assim como a reflexão sobre o trabalho do terapeuta ocupacional como apoiador matricial de um NASF com ênfase no cuidado à saúde da criança no território (A3). $\mathrm{O}$ artigo de comunicação livre contribuiu com reflexôes sobre as açôes da Terapia Ocupacional na APS referentes ao cuidado às pessoas com deficiência (A5).

O registro das informaçóes permitiu identificar os locais de vínculo profissional, os lugares de intervenção, os diferentes profissionais que realizam o apoio matricial, as situaçóes de saúde ou condiçóes sociais trabalhadas e a população beneficiada pelo apoio matricial em saúde realizado pelo terapeuta ocupacional (Tabela 3).

\section{Tipo de Serviço de Saúde onde É Realizado o Apoio Matricial pelo Terapeuta Ocupacional}

Os artigos selecionados apresentaram o terapeuta ocupacional como profissional que realiza o apoio matricial nas açóes e serviços da APS. Os cenários da prática profissional foram vinculados ao NASF
(A1), Centro de Saúde da Família (A2), Unidade de Saúde da Família (A3 e A4), Unidade Básica de Saúde (A5) e nas RAS pertencentes aos Estados do Ceará (A2), Pernambuco (A1) e São Paulo (A3, A4 e A5).

$O$ terapeuta ocupacional enquanto profissional apto a compor as equipes dos NASF é orientado a participar dos processos de análise e de intervençáo das equipes de referência sobre os problemas sanitários e necessidades de saúde comunitárias. As discussóes de casos, o atendimento compartilhado, a construção conjunta de projetos terapêuticos, a educação permanente $\mathrm{e}$ as açóes intersetoriais foram apresentadas nos materiais e representam possibilidades práticas e novos desafios profissionais no SUS.

\section{Os Profissionais que Realizam o Apoio Matricial com o Terapeuta Ocupacional}

O terapeuta ocupacional integrou equipes compostas por profissionais do campo da saúde, da educação e da assistência social. $\mathrm{O}$ apoio matricial em saúde realizado pelos terapeutas ocupacionais é amparado por equipes multiprofissionais compostas por assistente social (A1, A2, A3 e A4), farmacêutico (A1, A2, A3 e A4), fisioterapeuta (A1, A2, A3 e A4), fonoaudiólogo (A1 e A2), médico (A1 e A2), nutricionista (A1, A2, A3 e A4), psicólogo (A1, A2, A3 e A4), cirurgião-dentista (A2), educador físico (A2, A3 e A4), enfermeiro (A2 e A3), médico-veterinário (A2), agentes comunitários de saúde (A3), dentista (A3), auxiliar de dentista (A3) e auxiliar de enfermagem (A3). Dentre os trabalhos pesquisados, apenas um artigo não especificou os profissionais que promoviam o apoio matricial com o terapeuta ocupacional (A5).

Tabela 1. Relação dos artigos selecionados.

\begin{tabular}{cllll}
\hline Id. & \multicolumn{1}{c}{ Título } & Periódico & Ano & $\begin{array}{c}\text { Tipo de } \\
\text { publicação }\end{array}$ \\
\hline A1 & $\begin{array}{l}\text { A formação do terapeuta ocupacional e seu papel } \\
\text { no núcleo de apoio à saúde da Família - NASF } \\
\text { do Recife, PE. }\end{array}$ & CadTO - UFSCar. & 2014 & $\begin{array}{l}\text { Artigo original } \\
\text { resultante de } \\
\text { pesquisa. }\end{array}$ \\
\hline A2 & $\begin{array}{l}\text { A Terapia Ocupacional na residência } \\
\text { multiprofissional em saúde da família e } \\
\text { comunidade. }\end{array}$ & CadTO - UFSCar. & 2013 & $\begin{array}{l}\text { Relato de } \\
\text { experiência. }\end{array}$ \\
\hline A3 & $\begin{array}{l}\text { Apoio matricial e Terapia Ocupacional: uma } \\
\text { experiência de abordagem na saúde da criança. }\end{array}$ & Rev Ter Ocup - USP. & 2013 & $\begin{array}{l}\text { Relato de } \\
\text { experiência. }\end{array}$ \\
\hline A4 & $\begin{array}{l}\text { Reflexões sobre a prática do residente terapeuta } \\
\text { ocupacional na estratégia saúde da família no } \\
\text { município de São Carlos. }\end{array}$ & Rev Ter Ocup - USP. & 2013 & $\begin{array}{l}\text { Artigo original } \\
\text { resultante de } \\
\text { pesquisa. }\end{array}$ \\
\hline A5 & $\begin{array}{l}\text { Terapia Ocupacional em reabilitação na atenção } \\
\text { primária à saúde: possibilidades e desafios. }\end{array}$ & Rev Ter Ocup - USP. & 2011 & $\begin{array}{l}\text { Comunicação } \\
\text { livre. }\end{array}$ \\
\hline
\end{tabular}


Tabela 2. Relação dos artigos não selecionados.

\begin{tabular}{|c|c|c|c|c|}
\hline Título & Periódico & Ano & $\begin{array}{c}\text { Tipo de } \\
\text { publicação }\end{array}$ & Critério de exclusão \\
\hline $\begin{array}{l}\text { Atenção a usuários de drogas na rede } \\
\text { municipal de saúde: representações de } \\
\text { profissionais de saúde. }\end{array}$ & $\begin{array}{l}\text { CadTO - } \\
\text { UFSCar. }\end{array}$ & 2014 & $\begin{array}{l}\text { Artigo } \\
\text { original } \\
\text { resultante de } \\
\text { pesquisa. }\end{array}$ & $\begin{array}{l}\text { Não caracterizou a prática } \\
\text { de apoio matricial pelo } \\
\text { terapeuta ocupacional em } \\
\text { serviço de saúde. }\end{array}$ \\
\hline $\begin{array}{l}\text { Terapia Ocupacional na Atenção Primária à } \\
\text { Saúde: atribuições, ações e tecnologias. }\end{array}$ & $\begin{array}{l}\text { CadTO - } \\
\text { UFSCar. }\end{array}$ & 2012 & Ensaio. & $\begin{array}{l}\text { Não caracterizou a prática } \\
\text { de apoio matricial pelo } \\
\text { terapeuta ocupacional em } \\
\text { serviço de saúde. }\end{array}$ \\
\hline $\begin{array}{l}\text { Núcleo de Apoio à Saúde da Família e } \\
\text { Saúde Mental: itinerários terapêticos de } \\
\text { usuários acompanhados em duas Unidades } \\
\text { Básicas de Saúde. }\end{array}$ & $\begin{array}{l}\text { Rev Ter } \\
\text { Ocup - } \\
\text { USP. }\end{array}$ & 2012 & $\begin{array}{l}\text { Artigo } \\
\text { original } \\
\text { resultante de } \\
\text { pesquisa. }\end{array}$ & $\begin{array}{l}\text { Não caracterizou a prática } \\
\text { de apoio matricial pelo } \\
\text { terapeuta ocupacional em } \\
\text { serviço de saúde. }\end{array}$ \\
\hline $\begin{array}{l}\text { Metodologia de apoio matricial: interfaces } \\
\text { entre a Terapia Ocupacional e a ferramenta } \\
\text { de organização dos serviços de saúde. }\end{array}$ & $\begin{array}{l}\text { CadTO - } \\
\text { UFSCar. }\end{array}$ & 2012 & $\begin{array}{l}\text { Comunicação } \\
\text { livre. }\end{array}$ & $\begin{array}{l}\text { Não caracterizou a prática } \\
\text { de apoio matricial pelo } \\
\text { terapeuta ocupacional em } \\
\text { serviço de saúde. }\end{array}$ \\
\hline $\begin{array}{l}\text { Estratégia de Saúde da Família (ESF), } \\
\text { Núcleo de Apoio à Saúde da Família } \\
\text { (NASF) e Terapia Ocupacional: } \\
\text { problematizando as interfaces. }\end{array}$ & $\begin{array}{l}\text { Rev Ter } \\
\text { Ocup - } \\
\text { USP. }\end{array}$ & 2011 & Ensaio. & $\begin{array}{l}\text { Não caracterizou a prática } \\
\text { de apoio matricial pelo } \\
\text { terapeuta ocupacional em } \\
\text { serviço de saúde. }\end{array}$ \\
\hline $\begin{array}{l}\text { O projeto terapêutico singular como } \\
\text { estratégia de organização do cuidado nos } \\
\text { serviços de saúde mental. }\end{array}$ & $\begin{array}{l}\text { Rev Ter } \\
\text { Ocup - } \\
\text { USP. }\end{array}$ & 2011 & $\begin{array}{l}\text { Artigo } \\
\text { original } \\
\text { resultante de } \\
\text { pesquisa. }\end{array}$ & $\begin{array}{l}\text { Não caracterizou a prática } \\
\text { de apoio matricial pelo } \\
\text { terapeuta ocupacional em } \\
\text { serviço de saúde. }\end{array}$ \\
\hline
\end{tabular}

Ações de reabilitação de pessoas com deficiência na estratégia da saúde da família da Fundação Zerbini e Secretaria Municipal Rev Ter de Saúde de São Paulo - Região Sudeste Ocup -

- Sapopemba/Vila Prudente - período USP. 2009 Artigo 2000/2006.

\begin{tabular}{|c|c|c|c|c|}
\hline $\begin{array}{l}\text { A Terapia Ocupacional na Estratégia de } \\
\text { Saúde da Família - evidências de um estudo } \\
\text { de caso no município de São Paulo. }\end{array}$ & $\begin{array}{l}\text { Rev Ter } \\
\text { Ocup - } \\
\text { USP. }\end{array}$ & 2008 & Ensaio. & $\begin{array}{l}\text { Não atendeu ao critério } \\
\text { temporal estabelecido } \\
\text { para o estudo. }\end{array}$ \\
\hline $\begin{array}{l}\text { Desinstitucionalização e serviços } \\
\text { residenciais terapêuticos. }\end{array}$ & $\begin{array}{l}\text { Rev Ter } \\
\text { Ocup - } \\
\text { USP. }\end{array}$ & 2002 & Ensaio. & $\begin{array}{l}\text { Não atendeu ao critério } \\
\text { temporal estabelecido } \\
\text { para o estudo e não } \\
\text { caracterizou a prática } \\
\text { de apoio matricial pelo } \\
\text { terapeuta ocupacional em } \\
\text { serviço de saúde. }\end{array}$ \\
\hline
\end{tabular}

\section{População Atendida, Objetivos e as Condições de Saúde e/ou Sociais Abordadas pelo Apoio Matricial}

A população beneficiada pelo apoio matricial foi representada por crianças (A2, A3, A4 e A5), adultos (A2, A4 e A5) e idosos (A2, A4 e A5), que apresentaram necessidades relacionadas ao campo da saúde mental, da disfunção física e em situação de vulnerabilidade social. Familiares (A3 e A5), cuidadores informais (A3 e A5) e profissionais de saúde das equipes de referência (A3 e A5) também foram apresentados como participantes e beneficiários dessas práticas. $\mathrm{O}$ artigo $\mathrm{A} 1$ não apresentou especificações sobre o público-alvo e as condiçóes de saúde e/ou sociais abordadas no apoio matricial.

Os propósitos do apoio matricial do terapeuta ocupacional foram apoiar as equipes de referência em saúde por meio da oferta assistencial e da qualificação profissional. Para tanto, foram consideradas as características e as demandas dos territórios, em particular de como residiam as pessoas, informaçôes sobre os espaços sociais e comunitários, além das ofertas dos serviços de saúde (A3), para, assim, planejar 
Tabela 3. Descrição dos estudos segundo os serviços de saúde e municípios de atuação profissional, os profissionais que realizaram o apoio matricial, os participantes e as condições sociais e/ou de saúde abordadas pelo terapeuta ocupacional.

\begin{tabular}{|c|c|c|c|c|}
\hline Id. & $\begin{array}{c}\text { Serviços de saúde } \\
\text { e municípios } \\
\text { de atuação } \\
\text { profissional }\end{array}$ & $\begin{array}{c}\text { Profissionais que realizam } \\
\text { o apoio matricial }\end{array}$ & Participantes & $\begin{array}{c}\text { Situações de saúde ou } \\
\text { condições sociais abordadas }\end{array}$ \\
\hline A1 & $\begin{array}{l}\text { Núcleo de Apoio à } \\
\text { Saúde da Família, } \\
\text { município de } \\
\text { Recife-PE. }\end{array}$ & $\begin{array}{l}\text { Assistente social, } \\
\text { farmacêutico, fisioterapeuta, } \\
\text { fonoaudiólogo, médico, } \\
\text { nutricionista, psicólogo e } \\
\text { terapeuta ocupacional. }\end{array}$ & Não informado. & Não informado. \\
\hline $\mathrm{A} 2$ & $\begin{array}{l}\text { Centro de Saúde } \\
\text { da Família, } \\
\text { município de } \\
\text { Fortaleza-CE. }\end{array}$ & $\begin{array}{l}\text { Assistente social, } \\
\text { cirurgião-dentista, educador } \\
\text { físico, enfermeiro, } \\
\text { farmacêutico, fisioterapeuta, } \\
\text { fonoaudiólogo, médico, } \\
\text { médico-veterinário, } \\
\text { nutricionista, psicólogo e } \\
\text { terapeuta ocupacional. }\end{array}$ & $\begin{array}{l}\text { Crianças, adultos } \\
\text { e idosos. }\end{array}$ & $\begin{array}{l}\text { Desempenho ocupacional, } \\
\text { deficiência, dificuldades de } \\
\text { aprendizagem, saúde mental, } \\
\text { autonomia incapacidade e } \\
\text { funcionalidade, cuidados em } \\
\text { domicílio, risco ocupacional, } \\
\text { vulnerabilidade social. }\end{array}$ \\
\hline A3 & $\begin{array}{l}\text { Unidade de } \\
\text { Saúde da Família, } \\
\text { município de São } \\
\text { Carlos-SP. }\end{array}$ & $\begin{array}{l}\text { Agentes comunitários, } \\
\text { assistente social, dentista, } \\
\text { auxiliar de dentista, } \\
\text { educador físico, enfermeiro, } \\
\text { auxiliar de enfermagem, } \\
\text { farmacêutico, fisioterapeuta, } \\
\text { nutricionista, psicólogo e } \\
\text { terapeuta ocupacional. }\end{array}$ & $\begin{array}{l}\text { Crianças, família, } \\
\text { cuidadores e } \\
\text { profissionais de } \\
\text { saúde. }\end{array}$ & Vulnerabilidade social. \\
\hline A4 & $\begin{array}{l}\text { Unidade de } \\
\text { Saúde da Família, } \\
\text { município de São } \\
\text { Carlos-SP. }\end{array}$ & $\begin{array}{l}\text { Assistente social, educador } \\
\text { físico, farmacêutico, } \\
\text { fisioterapeuta, nutricionista, } \\
\text { psicólogo e terapeuta } \\
\text { ocupacional. }\end{array}$ & $\begin{array}{l}\text { Crianças, adultos } \\
\text { e idosos. }\end{array}$ & $\begin{array}{l}\text { Saúde mental, desenvolvimento } \\
\text { neuropsicomotor, trabalho e } \\
\text { vulnerabilidade social. }\end{array}$ \\
\hline A5 & $\begin{array}{l}\text { Unidade Básica de } \\
\text { Saúde, município } \\
\text { de São Paulo-SP. }\end{array}$ & Não especificado. & $\begin{array}{l}\text { Crianças, adultos, } \\
\text { idosos, família, } \\
\text { cuidadores e } \\
\text { profissionais de } \\
\text { saúde. }\end{array}$ & $\begin{array}{l}\text { Deficiência, incapacidade e } \\
\text { vulnerabilidade social. }\end{array}$ \\
\hline
\end{tabular}

e empenhar as suas intervençóes em conjunto com outros atores para além do espaço físico das unidades de saúde (JARDIM; AFONSO; PIRES, 2008).

No que se refere ao apoio matricial voltado para a assistência à saúde, o objetivo da intervenção do terapeuta ocupacional foi no sentido de favorecer o desempenho ocupacional para o autocuidado pessoal (A2), podendo envolver os familiares e os cuidadores informais. A prevenção de doenças e agravos, o tratamento integral, a adaptação e a reabilitação (A1 e A5), sob a perspectiva da promoção da saúde (A4), foram identificados como diretrizes das intervençóes. O desenvolvimento de propostas territoriais, visando facilitar a longitudinalidade nos cuidados em saúde (A5), o favorecimento da participação das pessoas com deficiência e em sofrimento mental na comunidade (A1) e o controle social nos serviços de saúde (A4) também fizeram parte dos objetivos do apoio matricial.

O apoio matricial voltado para a qualificação profissional em saúde buscou apresentar aos profissionais conhecimentos sobre os domínios da Terapia Ocupacional (A1) e, considerando as demandas do território, instrumentalizá-los com ferramentas da clínica ampliada (A2), de forma a qualificar a gestão do cuidado interdisciplinar em saúde.

Os resultados da pesquisa corroboraram a proposta de organização do trabalho das equipes matriciais, as quais apresentaram como objetivo do apoio matricial: promover a valorização do trabalho em equipe por meio de ações em conjunto no acolhimento, nas consultas compartilhadas, nas discussóes de caso e nas práticas intersetoriais (A1), ou mesmo pelo apoio 
pedagógico (A1 e A2) por intermédio da educação permanente em saúde (A3, A4 e A5) (Tabela 4).

O comprometimento do profissional na assistência à saúde foi identificado por meio do trabalho compartilhado e interdisciplinar (A1 A2, A3 e A4). As necessidades clínicas e sociais, além das especificidades e priorizaçôes dadas pelas equipes de referência, para cada ciclo de vida assistido, foram consideradas nos planejamentos das açôes de apoio matricial realizadas. Os profissionais valorizaram as demandas apresentadas pelas equipes de referência, ou mesmo observadas no território, reconhecendo o trabalho realizado e a experiência da pessoa na situação de doença e/ou da incapacidade. Os terapeutas ocupacionais se mostraram empenhados em implementar ações intersetoriais por meio de redes assistenciais, de forma a efetivar respostas às demandas do território acompanhado (A1, A2, A3, A4 e A5).
O profissional apresentou um conjunto diversificado de atividades e de açóes em suas experiências de apoio matricial (Tabela 5).

\section{Características do Apoio Matricial}

Para a realização do apoio matricial, foram utilizadas diferentes estratégias de intervenção, considerando a equipe de referência e a população-alvo beneficiada pela ação. Destacaram-se as ações de atendimento individual (A4) e grupal (A1, A2, A3, A4 e A5), a assistência domiciliar (A1, A3, A4 e A5), o apoio na construção de Projetos Terapêuticos Singulares (PTS) (A1, A4 e A5), as açôes intersetoriais compartilhadas (A1, A3, A4 e A5) e as açóes de educação permanente em saúde (A3, A4 e A5).

Tabela 4. Descrição dos estudos segundo os objetivos do apoio matricial pelo terapeuta ocupacional.

Id. Objetivos do terapeuta ocupacional no apoio matricial

Apresentar a profissão aos usuários e profissionais de saúde; prevenir doenças e incapacidades;

A1 promover a saúde e a integração social no campo da reabilitação e da saúde mental; promover assistência integral à saúde pelo desempenho funcional.

Instrumentalizar as equipes de saúde da família com ferramentas da clínica ampliada; favorecer a

A2 prevenção de agravos, o tratamento, a adaptação e a reabilitação; proporcionar o autoconhecimento e o autocuidado em saúde.

A3 Contribuir para o desenvolvimento infantil de forma integral.

A4 Prevenir doenças e promover saúde; fortalecer a participação popular e o controle social na unidade de saúde.

Detectar e intervir precocemente em alterações da funcionalidade; desenvolver propostas a problemas coletivos e individuais de redução de incapacidades e deficiências, de melhora da qualidade de vida,

A5 de favorecimento da participação social, da constituição das redes sociais de apoio e da eliminação de preconceitos, discriminações, exclusão social e segregação; facilitar a longitudinalidade nos cuidados em saúde.

Tabela 5. Descrição dos estudos segundo as atividades realizadas pelo terapeuta ocupacional.

Id. Atividades específicas realizadas pelo terapeuta ocupacional

Acolhimento, ações de sala de espera e ações de território; ações intersetoriais; articulação com

A1 equipamentos sociais, assistência técnico-pedagógica, consulta compartilhada, construção de Projeto Terapêutico Singular, discussões de caso, escuta qualificada, encaminhamento, grupos de educação em saúde e visita domiciliar.

A2 Atividades grupais.

A3 Ações de educação permanente em saúde, ações intersetoriais e ações de território; atividades grupais, reuniões de equipe e visitas domiciliares.

Ações de apoio institucional, ações de educação permanente em saúde, ações intersetoriais, assistência

A4 individual e grupal, discussão de caso; construção de Projeto Terapêutico Singular, reuniões de equipe e visitas domiciliares.

Acolhimento das demandas das equipes e apoio matricial; ações de promoção da saúde e prevenção de agravo; ações de educação em saúde; ações de educação permanente em saúde; ações intersetoriais; atendimentos individuais, grupais e familiares nas atividades de vida diária, na inclusão escolar e no

A5 campo do trabalho; atendimentos domiciliares; atividades grupais; construção de Projeto Terapêutico Singular; divulgação do trabalho de reabilitação com a comunidade; estudos sobre o território; facilitação da constituição de ambientes domiciliares e nos serviços de saúde; promoção do acesso a equipamentos de Tecnologia Assistiva; reuniões de equipe. 
Os atendimentos individuais e as assistências domiciliares eram voltados para o envolvimento dos usuários em atividades de cuidado à saúde e/ou de participação na comunidade. $\mathrm{O}$ artigo $\mathrm{A} 4$ apresentou a experiência do terapeuta ocupacional no envolvimento da pessoa em serviços da rede de saúde mental e em alternativas de trabalho e renda cooperativa sob a perspectiva da economia solidária.

As atividades grupais tiveram como foco as açôes de prevenção de doenças e agravos, além de promoção de saúde, direcionadas às pessoas de diferentes faixas etárias e demandas. Foram referidas atividades grupais com: mulheres; gestantes; idosos; pessoas com hanseníase, hipertensão e ou diabetes; crianças em vulnerabilidade social ou com alteraçóes no desenvolvimento neuropsicomotor; adolescentes no ambiente escolar; grupos de artesanato; caminhada; saúde do trabalhador; resgate das histórias do bairro; de saúde mental; linguagens artísticas com crianças e adolescentes e puericultura. Os grupos realizados pelos terapeutas ocupacionais buscaram proporcionar a informação, a convivência, a socialização e a intervenção ocupacional por meio da realizaçáo de atividades.

Segundo Furlan e Campos (2010), os grupos buscam contemplar açóes coletivas de caráter educativo, de aprendizado de diversas formas de viver e lidar com a doença, de esclarecimento, de mudança de hábitos, e que também almejam a formação de um espaço para criaçáo ou fortalecimento de redes sociais e para a experimentação de novas formas de viver.

Para Ballarin (2007), o grupo é um recurso importante para a Terapia Ocupacional, podendo ser abordado por intermédio de atividades significativas e expressivas, manifestando conteúdos internos e/ou externos, e permitindo experimentação com o próprio fazer. Por meio da intervenção grupal, foi possível o profissional proporcionar à comunidade reflexóes sobre: os problemas vividos; a expressão verbal e náo verbal; a superação e a resoluçáo de conflitos internos; o autoconhecimento e o autocuidado; o processo de conhecimento e de reconhecimento quanto à saúde e doenças; as mudanças de hábitos; a prevenção de doenças e agravos; os momentos de descontração; as trocas de experiências; o lazer; a interação social e a criação de vínculos, entre outros (PAIVA et al., 2013).

A construção do PTS favoreceu a discussão de casos entre o terapeuta ocupacional, os profissionais do NASF, os profissionais das equipes de referência de saúde e os usuários (A4). O PTS é um instrumento estratégico elaborado por uma equipe multidisciplinar a partir das necessidades dos usuários (BOCCARDO et al., 2011). Para além do planejamento das ações de cuidado individual ou grupal, esse instrumento contribuiu para as açóes intersetoriais de cuidado (A1) e para a educação permanente em saúde dos profissionais (A3, A4 e A5).

As açôes intersetoriais buscaram envolver o terapeuta ocupacional no trabalho em diferentes equipamentos assistenciais no território (A3 e A4). As experiências apontaram grande importância para o trabalho desse profissional na articulação de açóes intersetoriais. Sobre o tema da deficiência, o profissional apoiou a participação dos indivíduos na comunidade por meio do fomento de novos processos institucionais que visaram a melhorias da urbanização dos bairros, seja pela demarcação de vagas inclusivas nas escolas, pelo acesso de benefícios sociais, possibilidades alternativas de trabalho, implementação de linhas de ônibus acessíveis, enfrentamento de preconceitos, discriminaçôes, estigmas, entre outras tantas necessidades da população com deficiência (A5).

A educaçáo permanente em saúde buscou conduzir discussóes, produzir conhecimentos e direcionamentos às questóes, de forma a ampliar a visão da equipe para responder às demandas de crianças/adolescentes e corresponsabilizar-se com a equipe para a implementação de processos educacionais não formais de aprendizagem a partir da troca de experiências (A3). $\mathrm{O}$ artigo $\mathrm{A} 4$ apresentou a educação permanente sobre os temas Terapia Ocupacional, dependência química e manejo de grupo em reunióes de equipe. A condução desses processos trouxe novas perspectivas para a compreensão dos casos atendidos e na apreensão das dinâmicas do território e dos processos de trabalho das equipes matriciadas.

As reuniōes de apoio matricial e as conversas informais foram apresentadas como importantes espaços para que os profissionais pudessem expor as suas funçôes, capacidades, competências e objetivos no trabalho de apoio matricial (A1, A3, A4 e A5) (Tabela 6).

\section{Desafios ao Terapeuta Ocupacional para o Desenvolvimento do Apoio Matricial}

Foram identificados desafios inerentes ao trabalho de apoio matricial pelo terapeuta ocupacional.

Os materiais apontaram desafios que sugerem mudanças na formação profissional (A1), inovação instrumental e técnica do terapeuta ocupacional (A2, A3 e A4) e trabalho em equipe no exercício do apoio matricial (A4 e A5). Outros desafios encontrados 
Tabela 6. Descrição dos estudos segundo os desafios da prática profissional de apoio matricial.

Id. Desafios da prática profissional de apoio matricial

Ausência de conhecimento sobre os objetos de estudo e de intervenção da Terapia Ocupacional;

A1 compreensão dos usuários às intervenções do profissional; falta de efetividade das políticas públicas; envolvimento de instrumentos de trabalho e recursos para as intervenções, além da precária formação acadêmica para o trabalho no NASF.

A2 Construção de uma nova práxis para a Terapia Ocupacional na Estratégia Saúde da Família.

A3 Ação transdisciplinar, integral e intersetorial; incorporação do usuário no planejamento do seu projeto de cuidado.

Compreensão e aceitação do trabalho do terapeuta ocupacional pelas equipes de referência e demais profissionais de saúde; definição de papéis profissionais nas equipes; envolvimento profissional no processo de trabalho em unidades de saúde; inserção profissional e pessoal no campo; intervenção nas diferentes necessidades de saúde nos territórios.

A5 Integração do trabalho do terapeuta ocupacional com as equipes profissionais; envolvimento de instrumentos de trabalho e recursos para as intervenções.

se referiram ao processo de implementação dos NASF e dos investimentos institucionais para que o apoio matricial respondesse aos seus propósitos nas RAS (A1 e A5).

Sobre esse desafio, Reis, Gomes e Aoki (2012) afirmam que muitos profissionais não dispóem de ferramentas essenciais para uma intervenção que se propóe atender à complexidade das condiçóes, das necessidades e demandas de saúde, dificultando a construção de estratégias assistenciais no âmbito individual e para com as equipes de referência. Lancmam e Barros (2011) alertam para as possíveis fragilidades da proposta do apoio matricial quando este é direcionado para substituir serviços assistenciais especializados nas RAS.

Para lidar com a complexidade das demandas assistenciais e das necessidades do terapeuta ocupacional, os materiais indicaram a reorganizaçáo do trabalho multiprofissional como importante - e difícil - estratégia para o aprimoramento profissional (A1, A3 e A4). O terapeuta ocupacional foi convidado a conhecer e a aprender sobre alguns instrumentos de intervenção da saúde coletiva, tais como trabalho em equipe multiprofissional, intersetorial e participação do usuário no planejamento da intervenção (A1, A3 e A4).

Esse ponto, especificamente, remete aos campos e núcleos de saberes, conforme apontado por Campos (2000). Esse autor aponta como campo de saberes um determinado conjunto de conhecimentos compartilhados por grupos de profissionais que faz parte de uma mesma área de conhecimento. O campo se constitui, portanto, como "um espaço de limites imprecisos onde cada disciplina e profissão buscariam em outras apoio para cumprir suas tarefas teóricas e práticas" (CAMPOS, 2000, p. 220). Já o núcleo de saberes se constitui como conhecimentos específicos que definem os objetos de atuação das profissóes que compóem determinado campo de saber.

O apoio matricial é uma ferramenta de prática de saúde do campo da saúde coletiva. A Terapia Ocupacional pode contribuir com o seu núcleo de saberes, utilizando-se dessa ferramenta. $\mathrm{O}$ apoio matricial realizado pelo terapeuta ocupacional se apresentou como prática interdisciplinar pela construção coletiva de projetos e de intervenção multiprofissional com a população. $\mathrm{O}$ terapeuta ocupacional dialogou com diferentes núcleos de saberes profissionais, de forma a responder às demandas de cuidado, participação, educação e formação em saúde nos territórios assistenciais da APS.

Os estudos não aprofundaram o uso das atividades ou de ocupaçóes nas intervençóes do apoio matricial. Nesse sentido, as atividades humanas e as ocupaçóes, como objetos de fundamentação e intervenção da Terapia Ocupacional, nas práticas de apoio matricial, merecem ser mais bem compreendidas (SOUZA; AYRES; MARCONDES, 2012).

\section{Conclusões}

A pesquisa apontou que os terapeutas ocupacionais realizam o apoio matricial em saúde em serviços da APS por meio de sua vinculação profissional com o NASF. O apoio matricial em saúde às equipes de referência e aos profissionais do NASF buscou responder a demandas assistenciais e técnicas, referidas ou adscritas, das equipes de referência em saúde.

As açóes do apoio matricial investiram no trabalho em equipe para a educação permanente em saúde e para a assistência integral no âmbito individual, familiar e coletivo. $\mathrm{O}$ profissional demonstrou atuar no âmbito da prevenção de doenças e agravos, da promoção de saúde, da reabilitação, da adaptação e da 
educação em saúde em domicílios e estabelecimentos assistenciais no território.

As práticas estudadas indicaram o apoio matricial como possível e importante ação profissional na APS. O apoio realizado pelo terapeuta ocupacional apresentou: o seu envolvimento nos processos de mudança organizacional e assistencial de equipes de saúde; a articulação de saberes para o planejamento e intervenção compartilhada; o esforço para responder às demandas apresentadas no cotidiano do trabalho; as ofertas pedagógicas e assistenciais sobre o desempenho ocupacional; o estímulo para a produção de novos conhecimentos em equipe; o investimento em práticas em novos lugares e espaços no território.

Os desafios apresentados apontaram para a necessidade de aprimorar os conhecimentos sobre o trabalho interdisciplinar, a metodologia de apoio matricial e a fundamentação para a prática da Terapia Ocupacional na APS, de forma com que profissionais de saúde e os usuários do SUS identifiquem e compreendam os propósitos do seu trabalho.

Nesse sentido, o núcleo de saberes da Terapia Ocupacional contribui para o apoio matricial quando o profissional assume processos de intervenção que reconhecem as necessidades dos usuários e as tecnologias utilizadas por outros profissionais de saúde em práticas no território, para além das estruturas físicas dos centros de saúde, amparado pela sua compreensão de cotidiano e pautado nos possíveis modelos de saúde e de Terapia Ocupacional utilizados para esse fim.

A realização do apoio matricial requer do profissional de saúde o desenvolvimento de habilidades que superem o olhar hegemônico da clínica, considerando os processos de mudança, tanto organizacionais quanto assistenciais, as reais necessidades de saúde da população, os interesses e saberes profissionais das equipes de saúde, as contradiçôes, disputas e afetos existentes nos espaços de saúde.

É importante ampliar os investimentos na formação acadêmica do terapeuta ocupacional voltado para o apoio matricial em saúde, bem como o conhecimento tanto dos parâmetros assistenciais quanto do próprio objeto de intervenção do terapeuta ocupacional, no sentido de ampliar o escopo de açáo profissional para a consolidação da Terapia Ocupacional na prática do apoio matricial.

\section{Referências}

BALLARIN, M. L. G. S. Abordagens grupais. In: CAVALCANTI, A.; GALVÃO, C. Terapia Ocupacional: fun- damentação \& prática. Rio de Janeiro: Guanabara Koogan, 2007. p. 38-41.

BEIRÃO, R. O.; ALVES, C. K. A. Terapia ocupacional no SUS: refletindo sobre a normatização vigente. Cadernos de Terapia Ocupacional da UFSCar, São Carlos, v. 18, n. 3, p. 231-246, 2010.

BERTAGNONI, L. et al. Núcleo de Apoio à Saúde da Família e Saúde Mental: itinerários terapêuticos de usuários acompanhados em duas Unidades Básicas de Saúde. Revista de Terapia Ocupacional da Universidade de São Paulo, São Paulo, v. 23, n. 2, p. 153-162, 2012.

BOCCARDO, A. C. S. et al. O projeto terapêutico singular como estratégia de organizaçáo do cuidado nos serviços de saúde mental. Revista de Terapia Ocupacional da Universidade de São Paulo, São Paulo, v. 22, n. 1, p. 85-92, 2011.

BRASIL. Ministério da Saúde. Lei no 8080, de 19 de setembro de 1990. Dispóe sobre as condiçóes para a promoção, proteção e recuperação da saúde, a organização e o funcionamento dos serviços correspondentes e da outras providências. Diário Oficial [da] República Federativa do Brasil, Brasília, DF, 20 set. 1990. Disponível em: <http:// portal.saude.gov.br/portal/arquivos/pdf/lei8080.pdf>. Acesso em: 15 maio 2015.

BRASIL. Ministério da Saúde. Secretaria de Atenção à Saúde. Departamento de Atenção Básica. Diretrizes do NASF - Núcleo de Apoio à Saúde da Família. Brasília: Ministério da Saúde, 2009. (Cadernos de Atenção Básica no 27).

BRASIL. Decreto no 7.508, de 28 de junho de 2011. Regulamenta a Lei $n^{\circ} 8.080$, de 19 de setembro de 1990, para dispor sobre a organização do Sistema Único de Saúde - SUS, o planejamento da saúde, a assistência à saúde e a articulação interfederativa, e dá outras providências. Diário Oficial [da] República Federativa do Brasil, Brasília, DF, 28 jun. 2011a. Disponível em: <http://www.brasilsus. com.br/legislacoes/gm/108599-7508.html>. Acesso em: 15 maio 2015.

BRASIL. Ministério da Saúde. Portaria nº 2.488, de 21 de outubro de 2011. Aprova a Política Nacional de Atenção Básica, estabelecendo a revisão de diretrizes e normas para a organização da Atenção Básica, para a Estratégia Saúde da Família (ESF) e o Programa de Agentes Comunitários de Saúde (PACS). Diário Oficial [da] República Federativa do Brasil, Brasília, DF, 21 out. 2011b. Disponível em: <http://bvsms.saude.gov.br/bvs/saudelegis/gm/2011/ prt2488_21_10_2011.html>. Acesso em: 15 maio 2015.

CADERNOS DE TERAPIA OCUPACIONAL DA UFSCar. Submissões. São Carlos: UFSCar, 2015. Disponível em: <http://www.cadernosdeterapiaocupacional.ufscar.br/index.php/cadernos/about/ submissions\#authorGuidelines>. Acesso em: 09 jun. 2015.

CAMPOS, G. W. S. et al. A aplicação da metodologia Paideia no apoio institucional, no apoio matricial e na clínica ampliada. Interface - Comunicação, Saúde, Educação, Botucatu, v. 18, p. 983-995, 2014. Suplemento 1. 
CAMPOS, G. W. S. O anti-taylor: sobre a invenção de um método para co-governar instituiçóes de saúde produzindo liberdade e compromisso. Cadernos de Saúde Pública, Rio de Janeiro, v. 14, n. 4, p. 863-870, 1998.

CAMPOS, G. W. S. Saúde Púbica e Saúde Coletiva: campo e núcleo de saberes e práticas. Ciência e Saúde Coletiva, Rio de Janeiro, v. 5, n. 2, p. 219-230, 2000.

CAMPOS, G. W. S.; DOMITTI, A. C. Apoio matricial e equipe de referência: uma metodologia para gestão do trabalho interdisciplinar em saúde. Cadernos de Saúde Pública, Rio de Janeiro, v. 23, n. 2, p. 399-407, 2007.

FIGUEIREDO, M. D.; CAMPOS, G. W. S. O apoio Paideia como metodologia para processos de formação em saúde. Interface - Comunicação, Saúde, Educação, Botucatu, v. 18, p. 931-943, 2014. Suplemento 1.

FURLAN, P. G.; CAMPOS, G. W. S. Os grupos na atenção básica á saúde. In: BRASIL. Ministério da Saúde. Secretaria de Atenção à Saúde. Política Nacional de Humanização. Cadernos HumanizaSUS. Brasília: Ministério da Saúde, 2010. p. 105-116. (Série B. Textos Básicos de Saúde).

GIL, A. C. Como elaborar projetos de pesquisa. São Paulo: Atlas, 2002.

GOMES, J. A.; BRITO, C. M. D. Apoio matricial e terapia ocupacional: uma experiência de abordagem na saúde da criança. Revista de Terapia Ocupacional da Universidade de São Paulo, São Paulo, v. 24, n. 1, p. 81-86, 2013.

JARDIM, T. A.; AFONSO, V. C.; PIRES, I. C. A terapia ocupacional na Estratégia de Saúde da Família - evidências de um estudo de caso no município de São Paulo. Revista de Terapia Ocupacional da Universidade de Sáo Paulo, Sáo Paulo, v. 19, n. 3, p. 167-175, 2008

LANCMAN, S.; BARROS, J. O. Estratégia de saúde da família (ESF), Núcleo de Apoio à Saúde da Família (NASF) e terapia ocupacional: problematizando as interfaces. Revista de Terapia Ocupacional da Universidade de São Paulo, São Paulo, v. 22, n. 3, p. 263-269, 2011.

LIMA, A. C. S.; FALCÃO, I. V. A formação do terapeuta ocupacional e seu papel no Núcleo de Apoio à saúde da família - NASF do Recife, PE. Cadernos de Terapia Ocupacional da UFSCar, São Carlos, v. 22, n. 1, p. 3-14, 2014.

MANGIA, E. F.; ROSA, C. A. Desinstitucionalização e serviços residenciais terapêuticos. Revista de Terapia Ocupacional da Universidade de São Paulo, São Paulo, v. 13, n. 2, p. 71-7, 2002.
MANHO, F; SOARES, L. B. T.; NICOLAU, S. M. Reflexóes sobre a prática do residente terapeuta ocupacional na estratégia saúde da família no município de São Carlos. Revista de Terapia Ocupacional da Universidade de São Paulo, São Paulo, v. 24, n. 3, p. 233-241, 2013.

MENDES, E. V. As redes de atenção à saúde. Ciência \& Saúde Coletiva, Rio de Janeiro, v. 15, n. 5, p. 2297-2305, 2010.

OLIVEIRA, M. M.; CAMPOS, G. W. S. Apoios matricial e institucional: analisando suas construçóes. Ciência \& Saúde Coletiva, Rio de Janeiro, v. 20, n. 1, p. 229-238, 2015.

PAIVA, L. F. A. et al. A Terapia Ocupacional na Residência Multiprofissional em Saúde da Família e Comunidade. Cadernos de Terapia Ocupacional da UFSCar, São Carlos, v. 21, n. 3 , p. 595-600, 2013.

REIS, F.; GOMES, M. L.; AOKI, M. Terapia ocupacional na Atenção Primária à Saúde: reflexôes sobre as populaçóes atendidas. Cadernos de Terapia Ocupacional da UFSCar, São Carlos, v. 20, n. 3, p. 341-350, 2012.

ROCHA, E. F.; KRETZER, M. R. Ações de reabilitação de pessoas com deficiência na estratégia da saúde da família da Fundação Zerbini e Secretaria Municipal de Saúde de São Paulo - Região Sudeste - Sapopemba/Vila Prudente - período 2000/2006. Revista de Terapia Ocupacional da Universidade de São Paulo, São Paulo, v. 20, n. 1, p. 59-67, 2009.

ROCHA, E. F.; PAIVA, L. F. A.; OLIVEIRA, R. H. Terapia ocupacional na Atenção Primária à Saúde: atribuiçóes, açóes e tecnologias. Cadernos de Terapia Ocupacional da UFSCar, São Carlos, v. 20, n. 3, p. 351-361, 2012.

ROCHA, E. F.; SOUZA, C. C. B. X. Terapia Ocupacional em reabilitação na Atenção Primária à saúde: possibilidades e desafios. Revista de Terapia Ocupacional da Universidade de São Paulo, São Paulo, v. 22, n. 1, p. 36-44, 2011.

SANTOS, J. A. T.; OLIVEIRA, M. L. F. Atenção a usuários de drogas na rede municipal de saúde: representações de profissionais de saúde. Cadernos de Terapia Ocupacional da UFSCar, São Carlos, v. 22, p. 61-69, 2014. Suplemento Especial.

SOUZA, C. C. B.; AYRES, S. P.; MARCONDES, E. M. M. Metodologia de apoio matricial: interfaces entre a Terapia Ocupacional e a ferramenta de organizaçáo dos serviços de saúde. Cadernos de Terapia Ocupacional da UFSCar, São Carlos, v. 20, n. 3, p. 363-368, 2012.

\section{Contribuição dos Autores}

Bruna e Camila realizaram a pesquisa bibliográfica nos bancos de dados, concepção do texto, seleção e análise dos artigos e redaçáo. Bruno e Alessandro Rodrigo orientaram e revisaram o texto. Todos os autores aprovaram a versão final do texto. 